\title{
¿América Latina desde Marx o Marx desde América Latina? Las tensiones entre la escritura idealista y la escritura materialista* $^{*}$
}

Fecha de entrega: 7 de noviembre de 2018

Fecha de evaluación: 18 de diciembre de 2018

Fecha de aprobación: 28 de enero de 2019

Jaime Ortega Reyna**

\section{Resumen}

En el presente trabajo se analizan las tensiones surgidas a partir de la pregunta ¿América Latina desde Marx o Marx desde América Latina? Para hacerlo se utilizan los conceptos de escritura idealista y escritura materialista, que identifican dos de las opciones más importantes en la producción teórica marxista. La primera se asocia a la perspectiva que concibe una forma universal de la historia, ligada a ciertos textos de Karl Marx y Friedrich Engels, continuada por la socialdemocracia alemana y cuyo punto máximo es la filosofía de Georg Lukács. Del otro lado están las perspectivas abiertas por el mismo Marx en ciertos segmentos de El capital y en sus cartas a Vera Zasúlich. Así mismo, se retoman algunas de las implicaciones de esta última opción en las

* El presente texto es producto de las investigaciones del autor en torno al pensamiento crítico, así como de sus intereses en torno a Marx y la relación con los estudios sobre América Latina. Citar como: Ortega Reyna, J. (2019). ¿América Latina desde Marx o Marx desde América Latina? Las tensiones entre la escritura idealista y la escritura materialista. Cuadernos de Filosofía Latinoamericana, 40(121), 189-213. DOI: https://doi.org/10.15332/25005375.5477

** Doctor en Ciencias Sociales, Uner (Concepción del Uruguay, Argentina). Investigador en teoría crítica. Profesor de la Unam y la UAm, y miembro de Tiempos Equívocos: Ia teoría critica desde los márgenes, podcast de marxismo y teoria crítica. Integrante del consejo de redacción de la Revista Memoria. Correo electrónico: jaime_ortega83@hotmail.com 
tradiciones latinoamericanas. Particularmente se señala la importancia de la obra de Álvaro García Linera.

Palabras clave: marxismo, marxismo latinoamericano, universalismo, García Linera.

\section{Latin America on the basis of Marx, or Marx on the basis of Latin America? Tensions between Idealist and Materialist Writing}

\section{Abstract}

The article analyzes the tensions arising from the question, Latin America on the basis of Marx, or Marx on the basis of Latin America? To that effect, it uses the concepts of idealist writing and materialist writing, which identify the two main options in Marxist theoretical production. The former is associated with the conception of a universal form of history, linked to certain texts by Karl Marx and Friedrich Engels, continued by German Social Democracy, and reaching its highest point in the philosophy of Georg Lukács. The latter has to do with the perspectives opened by Marx himself in certain sections of Capital and in his letters to Vera Zasúlich. The article also discusses some of the implications of this second option for Latin American traditions highlighting the importance of the work of Álvaro García Linera.

Keywords: Marxism, Latin American Marxism, universalism, García Linera.

\section{Introducción}

La pregunta que le da título al presente artículo fue recuperada de un segmento del trabajo de Martín Cortés (2015) titulado Un nuevo marxismo para América Latina, un profundo acercamiento a la multifacética obra de José María Aricó. En esta ocasión la retomamos, desanclándola de aquella figura central para la tradición crítica de la región, con la finalidad de avanzar hacia el planteamiento de una tensión que 
atraviesa todo aquello que se denomina genéricamente marxismo latinoamericano, pero que en realidad se ubica, desde los primeros avances de Karl Marx, en el terreno de la teorización sobre la historia.

Con la pregunta enunciada se señalan los dos caminos privilegiados que ha tomado la reflexión marxista en su conjunto, además de mostrar con ello cierta especificidad del discurso crítico. En un sendero que se bifurca han sido dos tipos de reflexión los que han dominado el espacio de la producción teórica. Por un lado, se asume que el planteamiento marxista existe bajo el esquema de una filosofía de la historia que permite trazar la universalidad del proceso de despliegue del capital independientemente de las configuraciones particulares, de modo que anuncia un devenir necesario. Por el otro, se señala la impronta específica, cualitativamente distinta, de un lugar de enunciación que permite asediar al pensador clásico haciéndolo dialogar con un horizonte de época distinto al suyo, tensionando así sus puntos ciegos, sus omisiones, sus dilemas, y planteando la existencia de formas diferenciadas del despliegue histórico.

Desde la temprana obra de José Carlos Mariátegui hasta las discusiones historiográficas sobre los “modos de producción”, pasando por las más diversas corrientes filosóficas (como lo fueron la "filosofía de la praxis" o el althusserianismo), todas las lecturas marxistas se han visto involucradas en una de esas dos opciones. Ambas han convivido, se han nutrido y se han combatido mutuamente. Es esta situación la que explica el caudal tan variado de posicionamientos en torno al tema y sus múltiples referencias al campo político e ideológico.

\section{La escritura de Marx: idealismo y materialismo}

A mediados de la década de los sesenta el nombre de Louis Althusser comenzó a ser conocido mundialmente. La obra del francés levantó tantas polémicas que sería imposible reseñarlas todas en forma breve. Sin embargo, existe una que es de sumo interés para lo que ahora queremos comunicar: su forma de abordar la obra de Marx.

Althusser arriesgó en distintos momentos hipótesis a propósito de como trabajar en torno a la obra del alemán. La primera y más famosa es la que refiere a la dicotomía entre la "juventud” y la "madurez". Con aquellas designaciones el filósofo francés pretendía demarcar no la maduración del cerebro (o del carácter) de un individuo, 
sino la distancia entre un espacio teórico de producción aún dependiente de otros (la filosofía política kantiana, la economía política, etc.) y uno independiente, novedoso. Para Althusser el aporte de Marx no descansa en "ver" lo que aquellas corrientes no lograron observar, sino en establecer un conjunto de nuevas coordenadas (es decir, otras preguntas) para pensar y ejercer la crítica de la sociedad capitalista en su conjunto.

La asociación de las categorías utilizadas por Althusser con la vida del individuo Marx causó grandes confusiones y múltiples malentendidos. Sólo en textos póstumos hemos logrado seguir el rastro de cómo el francés modificó aquella situación y arriesgó otras hipótesis de trabajo que son muy sugerentes para nuestro interés. Dos son las principales: la expuesta en Marx dentro de sus límites (2003) sobre la unidad ficticia de los textos y la concepción de idealismo y materialismo como dos posiciones en filosofía que conviven en todo texto teórico.

Comencemos por la segunda. Desde el punto de vista de Althusser (2017), en su ensayo Ser marxista en filosofía, el idealismo y el materialismo no son dos filosofías contrapuestas, sino dos tendencias que el discurso asume de manera reiterada. No se trata de la vulgar noción que asume el "idealismo" como el dominio de "ideas abstractas" que explican la "materia", ni viceversa. Con el nombre de idealismo y materialismo Althusser busca captar el devenir de dos posiciones teóricas y políticas.

Así, por idealismo entiende aquella posición de la filosofía que se ancla en la totalidad expresiva, el privilegio de la necesidad y una noción teleológica de la historia. Desde su famoso Para leer "El capital" había hecho crítica de la totalidad expresiva (Althusser, 1969, p. 105), la cual entendía como una formulación en la que la "parte" era siempre expresión del "todo" que la determinaba. Además, frente a los elementos considerados como necesarios optaba por abrir espacio para la contingencia en la historia. Y finalmente, realizó la crítica de la teleología que los conceptos anteriores expresaban cuestionando la noción de tiempo histórico (Althusser, 1969, p. 104) ${ }^{1}$ en su versión progresista, que presupone la sucesión ordenada de etapas.

1 Escribe Althusser sobre la continuidad y homogeneidad de esta concepción idealista: "La continuidad homogénea del tiempo es la reflexión en la existencia de la continuidad del desarrollo dialéctico de la Idea. El tiempo puede ser tratado así como un continuo en el cual se manifiesta la continuidad dialéctica del proceso de desarrollo de la Idea" (Althusser, 1969, p. 104). 
Por el contrario, el materialismo, tal como Althusser lo articula, contiene anclajes muy particulares, y aunque contraviene al idealismo, no se trata de una posición independiente de este. Así, el privilegio no estaba en el "todo", sino en la capacidad que tenía la "parte” para rebelarse ante las coordenadas impuestas. De aquí nace el concepto de sobredeterminación (Althusser, 1979, p. 71), es decir, la consideración de múltiples contradicciones de tal modo que una aparentemente secundaria puede mostrarse como la más importante en determinadas condiciones. Nace también de allí el concepto de autonomía relativa, que refiere cómo algunas instancias pueden eludir la determinación del todo pues cada "parte" o "región" de la totalidad contiene su propia legalidad, su propio ritmo histórico y sus contradicciones específicas. A ello se suma en los años setenta el lento avance del concepto de coyuntura como expresión de la capacidad de intervención de los agentes en las contingencias. Para Althusser, entonces, lo más importante no son los elementos considerados como parte de la "necesidad" de la historia, sino las múltiples contingencias que ocurren en ella, cuya máxima expresión se encuentra en las coyunturas. Por este concepto deben entenderse pues las rupturas de la continuidad y homogeneidad en el tiempo histórico ocasionadas por momentos de posibilidad de intervención. Finalmente, frente a una versión homogénea del tiempo histórico Althusser recogerá la noción de articulación para señalar que en una formación social se pueden entrelazar distintos modos de producción y generar con ello una potente herramienta para desmovilizar la posición del universalismo, que da por hecho el dominio pleno del capital.

Como puede observase, en esta disposición el idealismo se asociará, de manera genérica, con aquellas filosofías que, aun enfrentadas y distantes, mantengan un horizonte similar en su comprensión de categorías como totalidad, universalismo o progreso. Althusser buscó restituir en el marxismo otra tendencia, asociada a los nombres de Spinoza y Maquiavelo, para desmovilizar la fuerte presencia de Hegel. Ello excede nuestro interés en esta ocasión. Lo importante es que en la versión de Althusser un tosco "materialismo" no vence a un ingenuo "idealismo", como sucedió en cierta popularización del marxismo, sino que ambas corrientes conviven en toda filosofía y sobre todo en la de Marx.

Esto último nos lleva al segundo elemento que, como hemos mencionado, se desprende de este posicionamiento donde idealismo y materialismo conviven en permanente contradicción y no son dos filosofías independientes que se excluyen mutuamente. Althusser (2003) refiere que en el texto de El capital - y en realidad, 
en cualquier otro texto teórico - distintas posiciones filosóficas conviven de manera conflictiva, desgarrando con ello la aparente unidad. Con todo esto podemos señalar que la antigua confrontación entre "juventud” y "madurez" resulta sumamente estática pues no capta el movimiento de las distintas posiciones dentro de los textos de Marx. Althusser señala que el alemán también quedó prendado de ciertas posiciones "idealistas" (tal como Marx entiende el término), y que estas no se despejaron del todo nunca, sino que siguieron operando de manera constante. El filósofo francoárabe hace una corrección de su propia forma de trabajo, y con ello nos brinda herramientas útiles para realizar operaciones necesarias dentro de la obra de Marx.

Así pues, en este texto optaremos por los conceptos de escritura idealista y escritura materialista para continuar esta forma de trabajo que sigue la hipótesis de Althusser aplicada a algunos textos de Marx y de la tradición que este forjó. Entendemos por escritura idealista toda aquella referencia a un proceso universalizante, asociado a las "filosofías de la historia" o a la pretensión metodológica de una totalidad expresiva. En tanto que por escritura materialista nos referimos a todo aquello que deseche el devenir teleológico o cualquier sentido trascendental (más allá de las prácticas específicas).

Sostenemos entonces que en Marx ambas perspectivas pueden ser comprendidas en sus mecanismos de operación a partir de la dicotomía: ¿América Latina desde Marx o Marx en América Latina? Nuestro propósito es mostrar las tensiones, los puntos de inflexión, los anudamientos y las posibilidades productivas.

Así, con el nombre Marx no referimos exclusivamente a la biografía de un individuo, sino que con él denominamos en realidad un espacio de producción teórica, que tiene una característica muy peculiar cuando se le aborda. Quien expresó esto de mejor forma fue Bolívar Echeverría cuando escribió: “Leer a Marx resulta así llevando las cosas al extremo, emprender la tarea paradójica de escribir junto con él su propia obra" (Echeverría, 1986, p. 200). El espacio teórico que se ampara bajo el nombre de marxismo tuvo distintas lecturas que se volvieron intentos de (re)escritura. Ahora nos concentraremos en dos de ellas. 


\section{América Latina desde Marx}

La dimensión que denominamos escritura idealista, asociada al universalismo, quedó asentada a partir de las tempranas intervenciones de Marx; se reforzó por la vía de las incursiones de Engels, a través de quien se trasmitió a la socialdemocracia alemana (y en general a todo el socialismo europeo del siglo xIx) y encontró en el siglo $\mathrm{xx}$ un segundo aire en una refinada y potente reformulación en la obra de Lukács. Expondremos en este orden los distintos elementos del marxismo como filosofía de la historia.

Como hemos insistido, la escritura de Marx se tensa al momento de concebir el despliegue de la historia como una gran dialéctica en la que los elementos de la necesidad se imponen sobre los de la contingencia. A eso lo denominamos escritura idealista. La nomenclatura del desarrollo, la civilización y el progreso se refuerza como el mirador privilegiado. No se trata de una visión exclusivamente apologética pues justamente lo que el autor alemán permite es realizar la crítica de la sociedad burguesa, a partir de la cual se puede formular una escritura materialista, es decir, una escritura que escapa a cualquier teleología, determinismo o filosofía de la historia.

Pero esta situación es más palpable en algunos textos que en otros. Pongamos un par de ejemplos para ilustrar este punto. El Manifiesto comunista, sin duda un documento clave para la referida tradición política, es redactado cuando Marx aún no clarifica su teoría de la explotación, pero traza las principales líneas de demarcación entre la sociedad burguesa y el movimiento socialista. La admiración por el progreso que la burguesía ha contribuido a impulsar es perceptible desde el principio del documento: "La burguesía ha desempeñado en la historia un papel altamente revolucionario" (Marx, 2015b, p. 119). Para Marx la revolución de la totalidad de las relaciones de producción e intercambio ha generado un nuevo estatuto en el que, rematado con belleza por la popular frase de Marshall Berman, "todo lo sólido se desvanece en el aire" (Marx, 2015b, p. 120).

Las referencias al otro no occidental como víctima de la técnica moderna que lleva al progreso también están presentes:

Merced al rápido perfeccionamiento de los instrumentos de producción y el constante progreso de los medios de comunicación, la burguesía arrastra a la 
corriente de la civilización a todas las naciones, hasta las más bárbaras. Los bajos precios de sus mercancías constituyen la artillería pesada que derrumba todas las murallas de China y hace capitular a los bárbaros más fanáticamente hostiles a los extranjeros. (Marx, 2015b, p. 120)

Con ello Marx señala que quienes buscan reestablecer las condiciones previas a la sociedad burguesa, que se encuentra en proceso de universalización, deben ser considerados no como revolucionarios, sino como reaccionarios "ya que pretenden volver atrás la rueda de la historia” (Marx, 2015b, p.126). Todos esos segmentos del Manifiesto podemos catalogarlos como parte de una escritura idealista, en cuyo centro se encuentra la continuidad con una gran filosofía de la historia en la que el capital sustituye al espíritu o la razón. La civilización burguesa aparece como un paso obligatorio, necesario, al que todas las naciones "atrasadas" o "bárbaras" se enfrentarán tarde o temprano. Oponerse a dicho proceso aparece en el siglo xix como algo reaccionario, sancionándose aquí que solo transitando por los elementos de necesidad impuestos en la era del capital es posible pensar un horizonte emancipatorio.

Sin embargo, es bien sabido que en el propio Manifiesto Marx colocó un freno, es decir, que la tensión existe y es perceptible lo que hemos denominado escritura materialista. Si bien aplaude el progreso de la sociedad burguesa y se maravilla de su potencialidad, también señala cómo la nueva clase dominante es incapaz de controlar sus propias creaciones: "Se asemeja al mago que ya no es capaz de dominar las potencias infernales que ha desencadenado con sus conjuros” (Marx, 2015b, p. 122). La civilización, dice Marx, no produce solo abundancia o industria, sino también una guerra social permanente, que desgarra a las naciones y los pueblos. Aun con los matices que permite esta lectura en clave materialista, es claro que en el Manifiesto la tensión se resuelve por la vía de la escritura idealista, en cuyo centro se encuentra la filosofía de la historia.

Aún en su proceder posterior Marx no se deshizo de los elementos de filosofía de la historia presentes en textos como el Manifiesto. Cambiando radicalmente el lenguaje, en el famoso "Prólogo a la Contribución a la crítica de la economía política" de 1859 insistió, con ánimo pedagógico, en continuar ese emplazamiento conceptual. Múltiples veces citado, Marx expone ahí un desarrollo progresivo y lineal de la historia: “A grandes rasgos, podemos designar como otras tantas épocas de progreso en la formación económica de la sociedad el modo de producción asiático, el antiguo, el 
feudal y el moderno burgués" (Marx, 2015c, p. 249). Se trata de una línea progresiva, en la que finalmente se cerrara "la prehistoria de la sociedad humana" (Marx, 2015c, p. 249). El eco de la escritura idealista resuena con fuerza en estas últimas palabras. Y es que, si bien Marx ha superado los motivos iniciales de su reflexión, permanecen en él algunos signos que vuelven complejo el abandono de ciertas coordenadas.

Como es bien sabido, un tratamiento poco reflexivo de este texto dará paso a empobrecidas versiones, como el economicismo más vulgar. Existen dos motivos en esta época de la producción de Marx que trabajaron en favor de estas perspectivas. En primer lugar, su noción de la correspondencia entre la "superestructura jurídica y política" y la "estructura económica" pues al señalar dicho elemento se renuncia a la comprensión de los desajustes entre las instancias, las crisis y las irrupciones de los contingentes sociales. Esto contrasta visiblemente con sus análisis de coyuntura (el 18 brumario de Luis Bonaparte, por ejemplo), en donde la mencionada correspondencia no opera, sino que se privilegia la formación de las subjetividades y su capacidad de intervención. El otro elemento es el de privilegiar lo que Marx denomina fuerzas productivas (para decirlo con sencillez: la reducción del movimiento y capacidad de la sociedad a un conjunto de tuercas y tornillos) y su (aparente) contradicción con las relaciones de producción. Al dotarlas de autonomía y concederles un lugar central en la explicación, las fuerzas productivas ${ }^{2}$ aparecen como el demiurgo de la historia. En una versión extrema son el elemento que debe ser radicalmente desarrollado hasta que las relaciones sociales de la sociedad capitalista queden destrozadas por ese impulso técnico y productivo. La historia del siglo xx es justamente la negación de esta tesis pues por más catastróficas o destructivas que se tornen franjas importantes de esas fuerzas, lo cierto es que las relaciones sociales capitalistas las han llevado a su extremo sin las consecuencias esperadas.

Como puede verse, el Marx de 1848 está atravesado por la tensión entre una escritura idealista en clave de filosofía de la historia (el despliegue totalizante de la razón, de la Idea o de las fuerzas productivas) y los elementos materialistas, que despojan de cualquier sentido trascendental a su planteamiento - los cuales analizaremos en el

2 No es que las "fuerzas productivas técnicas" no tengan alguna importancia en el desarrollo de un marxismo no teleológico. De hecho, ellas se vuelven cruciales para el entendimiento de la forma social del capital dominante. Sin embargo, su autonomización y fetichización pueden llevar a versiones progresistas-tecnicistas. El eco-socialismo contemporáneo ha hecho crítica de esa tentación. Igualmente, Armando Bartra (2016) ha señalado que no se puede omitir que las "fuerzas productivas" son de hecho ya relaciones sociales. 
siguiente apartado-. Pero lo importante es recordar la tensión permanente entre un horizonte de época (la ideología del progreso), compartido con las grandes tradiciones del pensamiento (especialmente el denominado idealismo alemán), y su presencia en un corpus que pretende desarrollar una crítica integral de la civilización moderna. De a poco la elaboración marxista conservará algunos de estos elementos trasladándolos a otros campos de reflexión tanto teórica como política. Dado el escaso espacio que tenemos, abreviaremos en algunos ejemplos de esta herencia.

Los segmentos de la obra de Marx que arriba hemos citado, no lo olvidemos, gozaron de una gran difusión a lo largo y ancho del mundo. Señalar la persistencia de la escritura idealista en cuyo corazón se encuentran variaciones de una filosofía de la historia no implica, como veremos más adelante, diagnosticar que el espacio teórico inaugurado por Marx queda atrapado en aquella. Una veta importante reforzó estas nociones a partir de otros marcadores que consideraremos ahora de manera sucinta.

El primero de ellos refiere a cierta canonización hecha por Engels de la lectura de la obra de Marx en un sentido "lógico-histórico". Con ello se consolida la escritura idealista en cuyo centro se encuentra la perspectiva especulativa. En su reseña de la Contribución a crítica de la economía política define esto con claridad en un párrafo igualmente múltiples veces citado:

Por tanto, el único método indicado era el lógico. Pero este no es, en realidad, más que el método histórico, despojado únicamente de su forma histórica y de las contingencias perturbadoras. Allí donde comienza esta historia debe comenzar también el proceso discursivo, y el desarrollo ulterior de este no será más que la imagen refleja, en forma abstracta y teóricamente consecuente, de la trayectoria histórica; una imagen refleja corregida, pero corregida con arreglo a las leyes que brinda la propia trayectoria histórica; y así, cada factor puede estudiarse en el punto de desarrollo de su plena madurez, en su forma clásica. (Engels, 1985, p. 444)

De esta manera la construcción categorial era igualada al despliegue histórico. La resonancia idealista no deja de ser clara, como en Hegel, para quien las categorías lógicas eran al mismo tiempo categorías ontológicas (es decir, del ser). Desde esta perspectiva las determinaciones que requieren los conceptos no se encuentran aparte de la consideración sobre el desarrollo histórico. Se (re)introducía de ese modo en el 
marxismo de forma potente la noción desarrollista y progresiva de la historia. Así, el elemento más complejo era siempre el más desarrollado y se consideraba, por tanto, la clave de explicación de otros fenómenos aparentemente menos complejos y menos desarrollados, condenados a perecer. El siglo xIx deja su impronta claramente en la elección de esta categorización basada en la necesidad: la dialéctica de la historia es también la dialéctica de los conceptos. Debe insistirse que en los Grundrisse, un conjunto de manuscritos de 1857, el propio Marx se opuso a esta perspectiva:

En otro momento, antes de dejar este problema, será necesario corregir la manera idealista de exponerlo, que da la impresión de tratarse de puras definiciones conceptuales y de la dialéctica de estos conceptos. Por consiguiente, deberá criticarse ante todo la afirmación: el producto (o actividad) deviene mercancía; la mercancía, valor de cambio, el valor de cambio, dinero. (Marx, 2007, p. 77)

Sin embrago, a pesar de la propia crítica de Marx, el germen de esta noción quedó implantando: si lo más desarrollado del capitalismo es la antesala para una nueva forma civilizatoria que representa el socialismo, las diversas formas de la historia (sintomáticamente denominadas "premodernas" o "precapitalistas") tarde o temprano tendrían que tomar el mismo sendero. Las categorías del ser del capital (cuya versión empírica era la forma dada en Europa) eran las categorías históricas que toda nación o pueblo tendría que transitar.

Recordemos, a todo esto, que la misma tensión señalada en Marx opera en Engels. Fue este quien de manera más clara asumió la idea de pueblos sin historia. Más de un biógrafo ha señalado su impaciencia por que Marx se dedicara a estudiar ruso en lugar de concluir El capital. Pero Engels también dejó grandes aportes teóricos en clave materialista. En esto queremos ser muy claros pues no podemos endilgarle a él, como en cierta manera lo hizo Maximilien Rubel (2003), la responsabilidad de lo negativo en lo que después se conocerá como el marxismo soviético. Engels abrió el discurso materialista de la crítica de la economía política al joven Marx cuando este aún se encontraba enredado en las poderosas redes categoriales de los jóvenes hegelianos (Mazora, 2017); aportó de manera central al análisis del problema de la ciudad burguesa y la vivienda proletaria (Fuentes Morúa, 1991), y en su momento comprendió, junto a Marx, que el destino de los pueblos coloniales era el destino de la revolución en Occidente. Sobre este último punto, en torno al famoso caso de 
Irlanda escribió: "La historia de Irlanda nos enseña qué desgracia es para un pueblo haber subyugado a otro pueblo" (Engels, 2010, p. 363).

Sin embargo, los elementos que conforman la escritura idealista siguieron operando, y no de manera inocente pues esta traía consigo los elementos de una filosofía de la historia progresiva y una consideración metodológica especulativa. Una elección de esta naturaleza tiene obligadamente efectos políticos. En donde se pueden notar mejor estos es en la relación que los partidos socialdemócratas de la in Internacional establecieron con la política colonial. La crisis de la socialdemocracia a principios del siglo xx debe ubicarse como un efecto político de esta pervivencia de contenidos típicos de la escritura idealista, particularmente su consideración, en tanto filosofía de la historia, de que Europa era una geocultura responsable de "civilizar" al mundo colonial. Justificando con ello el sometimiento de los que después se denominaron pueblos coloniales, o en la jerga decimonónica, "pueblos sin historia".

De esta manera, a pesar de las distintas adscripciones políticas entre reforma y revolución, personajes tan disímiles como Karl Kautsky o Eduard Bernstein terminaron aceptando el autoproclamado papel civilizador de Europa. Así mismo, es bien conocido que los partidos que declararon su actitud antibelicista terminaron sumándose a la conservación del orden de sus naciones y del estatuto colonial. Esta tendencia se rompió con el advenimiento de la Revolución rusa y las resoluciones de la III Internacional, motivo de otra historia.

Finalmente, del lado contrario a la socialdemocracia y tras el fracaso de esta, la continuidad de la escritura idealista transitó en la obra de Georg Lukács a un terreno conceptual muy fino, anclado preferentemente en una noción epistemológica. Aunque no podemos decir que Lukács sea un filósofo de la historia o se encuentre cercado totalmente por aquel lenguaje, lo cierto es que comparte las conclusiones con este y de hecho las lleva a un nuevo terreno, que perdurará casi todo el siglo xx. Sin embargo, lo hace mediante la rehabilitación del corazón de la propuesta del idealismo, al menos en una versión "gnoseológica". La intervención del gran teórico húngaro dará nacimiento a una veta del marxismo que transitaría hacia Alemania en la denominada Teoría crítica de la sociedad.

Enfrentado abiertamente a la concepción de la II Internacional, Lukács lleva a algunas conclusiones, como decíamos, a un plano aún más radical al colocarlas 
no en la historia como campo autónomo, sino en el restablecimiento de la noción especulativa que no distingue entre proceso histórico y proceso de conocimiento. No por nada Lukács es reconocido como el padre del marxismo hegeliano pues su esfuerzo teórico regeneró la potencialidad del discurso del filósofo de Jena. Imitando a esta figura, en su obra no opera una diferencia entre epistemología, ontología e historia. De esta manera, Lukács no puede sino traer al campo del marxismo el viejo problema de la dialéctica histórica.

Ahí se resguarda toda la potencia que tiene Historia y conciencia de clase, un conjunto de ensayos escritos entre 1919 y 1923. Entre ellos, los primeros afianzan la idea de que el marxismo es ante todo un método de conocimiento universal para cualquier dinámica de la sociedad y cualquier época histórica. Lukács no se pregunta por el espacio de aplicación de dicho proceder: el método es universal. Esto es así porque la categoría más importante aplazada es la de totalidad: "El dominio de la categoría de totalidad es el portador del principio revolucionario de la ciencia" (Lukács, 2009, p. 121). Para el Lukács de 1923 la "parte” (es decir, los elementos específicos) apenas figura como un elemento digno de considerarse teóricamente pues siempre está supeditada al despliegue y la racionalidad del todo: "la consideración de todos los fenómenos parciales como momentos del todo, del proceso dialéctico entendido como unidad de pensamiento e historia" (Lukács, 2009, p. 122). No hay tensión posible pues el horizonte moderno haría desfavorable sucumbir a cualquier especificidad o anomalía en pos de la razón de la totalidad. La "parte" siempre será deudora y expresión de la totalidad, sin mayor posibilidad de autonomía.

De ahí que a partir de ese momento el marxismo gire en gran medida en torno al problema del método de conocimiento y los dilemas que tiene el modelo de exposición y de investigación. La propia obra de Lukács reafirma que el marxismo es un método general para analizar cualquier rincón de la vida social. Su obra es el último intento de reestablecer un gran sistema filosófico mediante el cual el marxismo podría pronunciarse absolutamente sobre todo rubro del pensamiento. Así, formula una estética, una ética, una ontología, una política y, por supuesto, una epistemología. Tímidamente esto queda reconocido por el mismo Lukács cuando habilita a Hegel dentro de esta relectura de Marx propiciada por la Revolución rusa:

El método filosófico de Hegel, que fue siempre al mismo tiempo — del modo más avasallador en la Fenomenología del Espíritu- historia de la filosofía y 
filosofía de la historia, no ha sido nunca abandonado en este punto por Marx. Pues la unificación dialéctica hegeliana de pensamiento y ser, la idea de su unidad como unidad y totalidad de un proceso, es también la esencia de la filosofía de la historia del materialismo histórico. Incluso la polémica materialista contra la concepción "idealista” de la historia se orienta más contra los epígonos de Hegel que contra el maestro mismo, el cual estaba en este punto más cerca de Marx de lo que este mismo habrá pensando a veces, en el curso de su lucha contra la cristalización idealista del método dialéctico. (Lukács, 2009, p. 129)

Este párrafo resulta muy valioso para apuntalar el presente apartado. Lukács acierta en decir que en más de un momento Marx se acercó al idealismo. Es esto lo que hemos denominado, siguiendo a Althusser, escritura idealista. Falla, sin embargo, en no captar las tensiones en el seno de su obra. Igualmente acertado es su diagnóstico evaluativo de las características del proceder que unifica la filosofía de la historia con el devenir (ser y pensamiento), pero es incapaz de reconocer sus consecuencias. Paradójicamente Lukács cree que está reestableciendo algo que en realidad nunca estuvo ausente: los efectos de la escritura idealista no se expresan solo en la admiración a Hegel o las loas a la dialéctica, sino en la efectiva idea de ver en el despliegue de la historia el movimiento de la totalidad del ser y el pensamiento. Lukács, al volverse el teórico más importante del "marxismo occidental”, de hecho abrió las puertas para que la escritura idealista continuara actuando, si bien desde un punto de vista epistemologicista, consagrando con ello la "universalidad del método".

El recorrido que hemos hecho ha tenido como finalidad exponer en grandes trazos una de las opciones que ha escogido el despliegue teórico marxista: la de considerar América Latina desde Marx. Ello implica que aquella es un objeto indiferente, que podría ser reemplazada por cualquier otro y que es estudiada desde el mirador de la universalidad del método o de las categorías en su exposición lógico-histórica. Esta ha sido una ruta muy socorrida: considerar el discurso de Marx como universal per se, sin problematizar la especificidad del despliegue histórico. Aquí América Latina sería un objeto más y no necesariamente tiene que aparecer en el discurso pues la propia obra de Marx daría ya las respuestas para el estatuto de aquella región o de cualquier otra. 


\section{Marx desde América Latina}

La contraposición se vuelve evidente. Hemos designado a la problemática de encarar a Marx desde América Latina como aquella que convoca a una escritura materialista. Es decir, buscamos escapar de toda teleología y explorar discursos en donde la "parte" se resiste y se rebela contra el todo. Ello ha implicado un trabajo teórico que permite abordar novedosamente a Marx y a segmentos de la tradición por él inaugurada. Dado el espacio del que se dispone, nos concentraremos en algunos momentos que consideramos importantes. En primer lugar, en los atisbos de la escritura materialista en El capital y el conjunto de manuscritos que responden a las situaciones no plenamente dominadas por el capital. Propondremos del primer y canónico texto una lectura que permita un acercamiento desde la realidad latinoamericana. Posteriormente, con los segundos, sugeriremos el paso hacia un Marx que permite abordar formas no capitalistas de la historia.

¿Cómo leer El capital desde América Latina? ¿Es posible una lectura no "lógicohistórica"? Estas preguntas han sido planteadas de manera constante por varios intelectuales a lo largo de la región, aunque no siempre de manera explícita. En el caso latinoamericano hemos visto desfilar por esa ruta a grandes producciones filosóficas como las de Enrique Dussel (1985), Franz Hinkelammert (1977) y Bolívar Echeverría (1986). El primero ha enlazado la categoría de exterioridad con el corpus marxista de madurez; el segundo ha desarrollado el problema del fetichismo-muerte versus el trabajo vivo como fuente de una economía para la vida; el tercero ha realizado una gran operación que permite construir una teoría materialista de la cultura a partir del concepto de valor de uso. Otros, como Osvaldo Fernández (1982) o Carlos Aguirre (1984) han interrogado segmentos específicos, especialmente los distintos niveles que implica el concepto de fetichismo.

De entre la producción teórica latinoamericana queremos destacar la obra de René Zavaleta, quien desde su exilio publicó una sugerente cantidad de trabajos en los que se interrogaba sobre la posibilidad de construcción de las categorías marxistas en horizontes no plenamente capitalistas. Zavaleta, boliviano de nacimiento, mexicano por adopción, logró captar la problemática de la teorización que implicaba el nombre de Marx: por un lado, la política y el Estado expresaban la diversidad del mundo; por otro, la economía capitalista lo enfrentaba a la uniformidad del globo. 
Zavaleta se pregunta qué era lo que al final se imponía en la lucha política entre esos dos momentos. Los denominó respectivamente lógica del lugar y lógica del mundo (Zavaleta, 1977, p. 39) y señaló que ambas dimensiones se encontraban tensadas todo el tiempo. Esta situación es la que nos permite plantear la necesidad de trabajo sobre la obra de Marx a partir del lugar específico de América Latina.

Comencemos por El capital (2000) en su tomo i, un texto tradicionalmente leído de manera líneal, sin otro tipo de trabajo teórico que lo problematice. Desde nuestro punto de vista, una lectura situada de aquel —es decir, desde América Latinadebería poner énfasis en la sección séptima, y particularmente en el capítulo xxIV. Como lo ha señalado recientemente Eduardo Grüner, ese capítulo tiene una gran relevancia para América Latina, al sentar su conquista las bases para la construcción del mercado mundial. Sin embargo, además de este señalamiento es preciso indicar de qué manera leer el texto de Marx.

Sostengo que en El capital coexisten distintas lógicas, que no se implican las unas a las otras y expresan tendencias que operan de múltiples maneras en el mundo social. En el orden de exposición habitual podríamos ir señalándolas: primero, una lógica de la equivalencia, que implica una transformación en el seno de la sociabilidad humana pues con ella es posible la abstracción universal del trabajo. El trabajo abstracto aparece no con la medición del gasto de energía, sino a partir de su consideración como un tiempo indistinto, más allá de cualidades particulares. El proceso de abstracción del contenido material permite que la dimensión formal se imponga y haga del intercambio de mercancías el eje articulador de una gran parte de la vida social.

Es aquí en donde se encuentran la potencia y el límite de la crítica de la economía política, que atiende la dimensión totalizante de lo mercantil, pero omite los puntos ciegos de dicho proceso. Así, el problema de las lecturas tradicionalmente ancladas al capítulo primero que refuerzan la escritura idealista es que eluden un conjunto de procesos y lógicas aledañas a la mercantil. Para sintetizar, el problema de partir y concentrase en el capítulo primero es que da como explicación cosas que deben ser explicadas (el dominio del trabajo abstracto sobre el concreto, la formulación del equivalente general, entre otras). Además, para el caso latinoamericano, debe recordarse, esta lógica no se encuentra totalizada pues convive con otras expresiones del trabajo concreto que no han sido subsumidas por el trabajo abstracto. 
Una segunda tendencia, denominada lógica de la transformación, tiene como eje de discusión el paso de la categoría de trabajo vivo a la categoría fuerza de trabajo, es decir, el proceso de conversión de dinero en capital, que solo puede ocurrir cuando el intercambio ha comenzado a generalizarse. Nos referimos al contenido central de la sección segunda de El capital, en donde se describe la ruptura silenciosa del equivalente a partir de la aparición y generalización de la única mercancía que crea valor. Sin embargo, debe recordarse que la universalización del equivalente no ocurre antes de este pasaje, sino de manera posterior. Es decir, no hay encadenamiento causal: la fuerza de trabajo en tanto que categoría moderna puede aparecer sin que el equivalente se realice en todos los poros de lo social. Lo demuestra la propia historia del conflicto social y no la cronología del método "lógico-histórico": el trabajo abstracto es resultado de la mercantilización del trabajo vivo y su devenir como fuerza de trabajo.

La tercera tendencia se materializa a partir de la lógica de la subsunción, que permite la producción de plusvalor y por tanto de capital. De nuevo, es pertinente insistir en que tanto esta lógica como la anterior, son las que permiten la existencia del trabajo abstracto y otras categorías expuestas en la sección primera. Cabe señalar, además, que fue esta lógica la más importante en la interpretación del marxismo en el siglo $\mathrm{xx}$, toda vez que permitía entender el llamado régimen de la fábrica, es decir, la concentración del proletario industrial en las cuatro paredes de la industria moderna. La confusión marxista consistió en señalar una característica pasajera como la figura principal y a veces única. En cambio, el capital produce más plusvalor sin la necesidad de las fábricas humeantes y sucias del siglo xIx. Para simplificar, y bajo la advertencia de los múltiples matices, señalamos que de la sección tercera a la sexta de El capital vemos operar esta lógica. Insistimos que sigue siendo pertinente en tanto que gran parte del uso de la fuerza de trabajo (particularmente en países asiáticos) vive una especie de "industrialización del siglo xix". Sin embargo, debe resaltarse que el capital para producir plusvalor no requiere, de manera obligada, de la figura prometeica del proletariado.

Finalmente, la que nos parece la lógica más importante en términos teóricos: la de la separación o desposesión, expresada en la sección séptima. Dice Althusser que a partir del capítulo xxiv de la obra cumbre de Marx encontramos 
el segundo gran descubrimiento de los increíbles medios con que se realizó la "acumulación primitiva” [...] que el capitalismo nunca ha dejado de emplear y que continúa empleando en pleno siglo $\mathrm{xx}$, "al margen" de su existencia metropolitana, es decir, en los países colonizados y excolonizados, los medios de la violencia más feroz. (Althusser, 2005, pp. 32-33)

El primer gran descubrimiento, para Althusser, no era el que se encontraba contenido en la sección primera (el trabajo abstracto o valor de uso), sino lo que hemos denominado la lógica de la subsunción, es decir, la posibilidad de la extracción de plusvalor. El segundo es la constatación de la forma en que se garantizan las condiciones para el resto de lógicas: aquellas que versan sobre la separación y la desposesión.

La relación social capitalista, que puede ser abordada desde miradas múltiples, conserva un punto medular: la acumulación del capital en todo momento implicará la expropiación de la soberanía de los sujetos en el proceso de reproducción de su vida. Dos filósofos españoles lo han dicho bien:

Es preciso insistir una vez más: aquí no se trata de recordar aquello que hizo capital al capital, sino aquello que hace capital al capital. No se trata de recordar una historia, sino de que esa historia nos permita "recordar", en un sentido inequívocamente platónico, una estructura. No se trata de una investigación sobre los orígenes históricos, sino de una investigación sobre las condiciones sin las cuales no hay modo capitalista de producción. No se trata de cómo "se formó" el modo de producción capitalista, sino de en qué consiste este modo de producción. (Fernández Liria y Zahonero, 2010, p. 427)

Efectivamente el corazón de la sección séptima es el capítulo xxIV, que en diversas ocasiones fue señalado como una mera demostración ilustrativa, sin ningún tipo de consistencia teórica. Desde nuestro punto de vista es este el capítulo teórico y político más importante de El capital leído desde América Latina. Con esto queremos decir que el texto de Marx opera aún como un instrumento útil para la lucha política pues en dicho capítulo se encuentra en gran medida el conjunto de determinaciones que permiten no que Marx explique América Latina, sino que quienes hacen la crítica práctica (es decir, en la lucha política) se apropien de Marx. Justamente porque allí no se plantean supuestos a priori históricos o metodológicos, sino las 
lógicas diferenciadas y encadenadas en las que opera la totalidad del orden social, que brindan el secreto del despliegue capitalista y permitien, por tanto, matizar los procesos a partir de las especificidades o particularidades.

Es cierto que ello requiere operar teóricamente sobre el texto, deslindando posibles vetas que hoy están canceladas. Nos referimos con ello a que el problema de la separación aludido en dicho capítulo no es ya el de la descampesinización clásica, que América Latina vivió con fuerza a mediados del siglo xx. Cierto es que no nos encontramos en la época de Marx, durante la cual se expropiaba el territorio con la finalidad de crear nuevos contingentes sociales para ser capturados por la relación social capitalista: la expulsión de campesinos para ser captados por el flujo social de la naciente fábrica social. El capital en su forma contemporánea no tiene su corazón en ese proceso, sino en otros distintos.

Estamos ante una situación que es iluminada por la lógica del capítulo xxIv: el proceso de destrucción de lo común, por la vía de la separación de diversos niveles de la vida social construidos a lo largo de la historia. Ello puede implicar la destrucción de formas de lo común ancladas en la historia o bien de construcciones más recientes, como las que refieren a lo público. Así, el capítulo en cuestión se muestra como una herramienta que permite configurar la crítica de la sociedad burguesa con la especificidad de la coyuntura.

Después de esta exposición nos parece apropiado señalar que en la sección séptima se encuentra la clave de la escritura materialista pues allí se expresan las condiciones de posibilidad para la reproducción de las relaciones sociales y cómo cada forma específica, en la historia, muestra la conjunción de los elementos que les darán concreción. La tensión entre contingencia y necesidad no tienen el ansiado estatuto de correspondencia y simultaneidad que prevalece en la escritura idealista.

Así, un trabajo diferenciado sobre los distintos segmentos de El capital permite notar que la potencia del materialismo se encuentra no en detectar el "origen" del valor, sino en la inacabada construcción del orden social capitalista, en cuyo centro se encuentra la destrucción de lo común a partir del despojo. Ahí, entonces, una forma de capitalismo (el industrial occidental) pierde su fuerza y nos permite captar que existen otros momentos, relaciones y espacios sobre los que el capital intenta actuar o actúa efectivamente y, por lo tanto, también se le resiste. Este planteamiento 
permite sacar la lucha de clases de las cuatro paredes de las fábricas modernas y plantearla como un horizonte que afecta todas las dimensiones de la convivencia en común de los seres humanos con la naturaleza.

Pero, ¿existen más elementos en la obra del propio Marx en los que podamos señalar este tipo de alternativas? Una muy señalada y que recogemos aquí es la de los planteamientos del alemán al final de su vida sobre la situación rusa. El tema se desata tras el cuestionamiento que hace una militante "populista" rusa a Marx:

Una de dos: o bien esta comuna rural, libre de las exigencias desmesuradas del fisco, de los pagos a los señores de la administración arbitraria, es capaz de desarrollarse en la vía socialista, o sea de organizar poco a poco su producción y su distribución de los productos sobre las bases colectivistas, en cuyo caso el socialismo revolucionario debe sacrificar todas sus fuerzas a la manumisión de la comuna y a su desarrollo. O si, por el contrario, la comuna está destinada a perecer no queda al socialista, como tal, sino ponerse a hacer cálculos, más o menos mal fundados, para averiguar dentro de cuántos decenios pasará la tierra del campesino ruso de las manos de este a las de la burguesía y dentro de cuántos siglos, quizá, tendrá el capitalismo en Rusia un desarrollo semejante al de Europa occidental. (Zasúlich 2015, p. 175)

Las dudas que la militante rusa planteaba generaron una verdadera posibilidad productiva insospechada hasta entonces. En tiempos recientes Armando Bartra (2016) ha señalado que aquella carta "descarriló la historia" y permitió a Marx ampliar sus horizontes con respecto a las diversas formas de esta, más allá de los caminos planteados en las consideraciones teleológicas. La respuesta de Marx tuvo que esperar un tiempo pues aquella situación de ser confrontado desde la especificidad de la "parte" que cuestiona al "todo" lo hizo rectificar. Largos borradores fueron redactados, pero nunca concluidos. Finalmente la respuesta se da en una breve misiva donde Marx señalaba que la comunidad rusa no tenía que desparecer como requisito para transitar a una forma no capitalista, ni tampoco el país debía pasar por las penurias de la geocultura dominante del capitalismo. Prácticamente en todos sus esbozos aparece la frase: 'La 'fatalidad histórica' de ese movimiento está, pues, expresamente restringida a los países de Europa occidental” (Marx, 2015a, p. 195). Finalmente en la sucinta respuesta Marx señala: 
El análisis presentado en El capital no da, pues, razones, en pro ni en contra de la vitalidad de la comuna rural, pero el estudio especial que de ella he hecho, y cuyos materiales he buscado en las fuentes originales, me ha convencido de que esta comuna es el punto de apoyo de la regeneración social en Rusia, mas para que pueda funcionar como tal será preciso eliminar primeramente las influencias deletéreas que la acosan por todas partes y a continuación asegurarle las condiciones normales para un desarrollo espontáneo. (Marx, 2015a, p. 204)

Este tema ha sido retomado primero por Theodor Shanin en un pionero ensayo; después por los latinoamericanos del grupo Pasado y Presente, especialmente José Aricó, y de manera reciente el mundo anglosajón lo recibió por medio del trabajo de Kevin Anderson. Así mismo, una sugerente lectura desde América Latina ha sido realizada por el ya mencionado Armando Bartra y por Álvaro García Linera. Sobre este último volveremos en nuestro último apartado.

Ahora solo queda señalar que hemos denominado escritura materialista justamente a las formulaciones del "último Marx", como lo llamó Dussel, que permiten mirar horizontes más amplios, lo que genera un concepto más abierto de la historicidad. Ello porque se vuelve una tarea política mostrar que el desarrollo del capitalismo no conduce al socialismo, que el despliegue de las fuerzas productivas no es condición de posibilidad de otra civilización mejor. Marx logró plantear esto en forma breve, de modo que permitiera entender que el desarrollo del capital no era necesariamente la antesala para su superación. Esto obliga a buscar otros resquicios, a ensayar nuevas relaciones y formas de producción y circulación, y sobre todo a considerar que todas esas relaciones antes señaladas como no modernas, no civilizadas, no desarrollas, pueden ser entendidas como no capitalistas y potenciadas como la base para lo poscapitalista.

\section{¿Qué lecciones quedan para el marxismo latinoamericano?}

De entre la producción latinoamericana reciente nos parece muy importante mencionar la que ha publicado Álvaro García Linera pues en ella se concentran de manera más sólida las distintas perspectivas de la escritura materialista. El hoy vicepresidente de Bolivia ha planteando una relectura de Marx específicamente 
desde América Latina. Sus primeros trabajos - De demonios escondidos y fantasmas de revolución, Crítica de la nación y la nación crítica y Forma valor, forma comunidad - muestran la potencialidad productiva de la relectura de Marx que se hace desde nuestra región.

Aquí sostenemos que los trabajos de este tipo apuntan, a pesar de su diversidad, a la desmovilización de lo que antes hemos denominado escritura idealista. Los pensadores latinoamericanos han sido los mejores receptores de esta posibilidad productiva, y han correspondido contribuyendo a una escritura materialista. Ponemos solo algunos ejemplos que justifican esta idea.

En De demonios escondidos y fantasmas de revolución García Linera hace una crítica radical de las concepciones progresistas de la historia que tenía la izquierda marxista boliviana. Ello le permite deducir claramente que el desarrollo de las fuerzas productivas no era equivalente al desarrollo del proletariado. Más aún, que a mayor despliegue del capitalismo en sus potencialidades técnicas, menor posibilidad de autonomía para la clase proletaria. Así, escribe tras trabajar sobre los Grundrisse:

Marx rechaza la identificación de "progreso capitalista" = fuerza proletaria. Sabe que lo primero es la condición de la segunda, pero una condición no suficiente, más aún, una condición que puede convertirse en su contrario, en el debilitamiento de la fuerza proletaria, en tanto el proletariado subordine sus intereses y su lucha a los del "progreso capitalista”. Hay pues un claro rechazo del determinismo económico, y saca a la luz la impostura de lo político. (García Linera, 1991, p. 101)

El escritor boliviano continuó en la exploración de vetas que cuestionaban el supuesto universalista. Así, en su obra Forma valor, forma comunidad realiza una compleja lectura de El capital de Marx haciendo énfasis no solo en la pretensión de universalidad del valor, sino sobre todo en las condiciones de su superación, que encuentra en la comunidad. El retorno a la comunidad lo llevó a estudiar los manuscritos de Marx, recientemente publicados. Así, en su estudio introductorio al Cuaderno Kovalevsky dice:

Esta concepción marxista de la diversidad del desarrollo histórico de los pueblos del mundo y su oposición a trazar caminos progresivos y obligados de 
historia, ciertamente es ya una continuación de las ideas expresadas por Marx en la redacción de El capital sobre las sociedades agrarias antiguas y, en particular, de los razonamientos desarrollados en los Grundrisse sobre las diversas sociedades que se desarrollaron con base en la comunidad originaria, como la formación económico-social [sic] eslava, germánica, asiática, etc. En conjunto, vemos pues en Marx una concepción del desarrollo histórico que difiere antagónicamente de los esquemas linealistas, esquemáticos y en ocasiones con rasgos racistas con que representantes de la II Internacional caracterizaron el desarrollo histórico. (García Linera, 2015, p. 108)

En suma, el marxismo latinoamericano en sus grandes expresiones prácticas - Mariátegui o la Revolución cubana, por ejemplo- nos ha otorgado avances teóricos significativos, toda vez que expresan la rebelión de la "parte" sobre la totalidad. La dimensión teórica efectivamente ha encontrado posibilidad productiva pues logra liberarse de las propuestas de una filosofía de la historia. Esta tendencia se ha apropiado de Marx renunciando a cualquier ortodoxia, y ha teorizado teniendo en cuenta las fuerzas políticas que ponen en cuestión la forma de dominación capitalista.

La obra de García Linera, con las dificultades propias de quien interviene en la coyuntura, expresa la continuidad de este hecho. Han sido los pueblos indígenas, con sus movimientos y partidos, los que han explorado nuevas formas de cuestionamiento del capitalismo en medio de las contradicciones de la época. Sin embargo, la lección teórica, y específicamente la que refiere a la relectura de la obra de Marx, puede seguir siendo explorada en esta producción. La demostración entonces parte de que una mirada específica — por más "periférica” que sea- permite asediar al clásico, replantearlo y volverlo más productivo.

\section{Referencias}

Aguirre, C. (1984). El problema del fetichismo en El capital. México: IIS.

Althusser, L. (1969). Para leer El capital. México: Siglo XXI.

Althusser, L. (1979). La revolución teórica de Marx. México: Siglo XXI.

Althusser, L. (2003). Marx dentro de sus límites. Madrid: Akal. 
Althusser, L. (2005). Crítica previa a la lectura de El capital. México: Paradigmas y utopías.

Althusser, L. (2017). Ser marxista en filosofía. Madrid: Akal.

Bartra, A. (2016). Hacia un marxismo mundano: la clave está en los márgenes. México: UAM-X.

Cortés, M. (2015). Un nuevo marxismo para América Latina. Buenos Aires: Siglo xxi.

Dussel, E. (1985). La producción teórica de Marx. México: Siglo xxi.

Echeverría, B. (1986). El discurso crítico de Marx. México: Era.

Echeverría, I. A. (2014). Memoria, utopía y liberación: las condiciones de lo posible desde la filosofía de la liberación de Franz Hinkelammert. Cuadernos de Filosofía Latinoamericana, 35(110), 193-212.

Engels, F. (1985). Marx. Contribución a la crítica de la economía política. En K. Marx y F. Engels, Obras escogidas. Tomo I (pp. 431-447). México: Quinto Sol.

Engels, F. (2010). Carta de Engels a Marx del 24 de octubre de 1869. En K. Marx y F. Engels, Collected works, Vol. 43: Letters 1868-70 (pp. 362-363). Londres: Lawrence \& Wishart.

Fernández, O. (1982). Del fetichismo de la mercancía al fetichismo del capital. Madrid: Literatura Americana Reunida.

Fernández Liria, C. y Zahonero, L. (2010). El orden de El capital. Madrid: Akal.

Figueroa, D. A. (2016). ¿ Historia de las ideas o genealogía de las prácticas? Creencias marxistas en el Perú. Cuadernos de Filosofía Latinoamericana, 37(114), 167-186.

Fuentes Morúa, J. (1991). Marx-Engels contra el despotismo urbano. México: UAM-I.

García Linera, A. (1991). De demonios escondidos y fantasmas de revolución. La Paz: Ofensiva Roja.

García Linera, A. (2015). Kovalevsky y Marx. En K. Marx, La comunidad ancestral (pp. 105-120). La Paz: Vicepresidencia del Estado Plurinacional de Bolivia.

Hinkelammert, F. (1977). Las armas ideológicas de la muerte. San José (Costa Rica): DEI. 
Lukács, G. (2009). Historia y conciencia de clase. Buenos Aires: Razón y Revolución.

Marx, K. (2000). El capital: crítica de la economía política. Madrid: Akal.

Marx, K. (2007). Elementos fundamentales para la crítica de la economía política (Grundrisse. 1857-1858). México: Siglo XXI.

Marx, K. (2015a). Karl Marx a Vera Zasúlich: 8 de marzo de 1881. En K. Marx, La comunidad ancestral (pp. 203-204). La Paz: Vicepresidencia del Estado Plurinacional de Bolivia.

Marx, K. (2015b). Manifiesto comunista. En H. Tarcus, Antología. Karl Marx (pp. 111-147). Buenos Aires: Siglo XXI.

Marx, K. (2015c). "Prólogo a la Contribución a la crítica de la economía política”. En H. Tarcus, Antología. Karl Marx (pp. 247-252). Buenos Aires: Siglo XXI.

Mazora, M. (2017). Marx, discípulo de Engels. Buenos Aires: UNSM.

Rubel, M. (2003). Marx sin mito. Barcelona: Octaedro.

Zavaleta, R. (1977). El poder dual: problemas de la teoría del Estado en América Latina. México: Siglo XXI.

Zasúlich, V. (2015). Vera Zasúlich a Marx: 16 de febrero de 1881. En K. Marx, La comunidad ancestral (pp. 175-176). La Paz: Vicepresidencia del Estado Plurinacional de Bolivia.

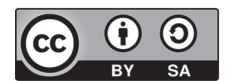

